\title{
스마트폰 중독
}

가톨릭대학교 의과대학 서울성모병원 정신건강의학과

나의현 · 김대진

\section{Smartphone Addiction}

\author{
Euihyeon Na and Dai-Jin Kim
}

Department of Psychiatry, Seoul St. Mary's Hospital, College of Medicine, The Catholic University of Korea, Seoul, Korea

Smartphones have significantly changed our lives and become a digital lifestyle hub. However, uncontrolled smartphone usage has created a new issue in global health, including a range of mental health concerns. Previous studies have proposed that excess use of a smartphone that interferes with daily life should be called "smartphone addiction", which has similar core features to substance-related disorders (substance addiction) and known behavioral addictions. The aim of this review was to add to our understanding of smartphone addiction by presenting an overview of the research field. (Korean J Med 2016;91:245-249)

Keywords: Smartphone addiction; Smartphone overuse; Internet addiction; Behavioral addiction

\section{서 론}

스마트폰(smartphone)은 기존 통신 수단의 단순한 발전이 아닌, 현대 인류에게 필요한 수많은 기능이 통합 내재된 휴 대용 컴퓨터로 여겨진다[1]. 최첨단 기술이라는 단어를 사용 하기에도 어색할 정도로 우리는 이미 스마트폰과 함께하는 삶을 살고 있다. 이는 2015년 말 기준으로 전 세계 스마트폰 사용자 수가 총 34 억 명이며, 2021년에는 2배 가까이 증가한 64억 명에 달할 것으로 전망하는 통계 수치에도 반영된다[2]. 특히 우리나라는 스마트폰 사용자 수가 2016년 현재 4천만
명을 넘겼으며, 스마트폰 보급률은 전 세계에서 가장 높은 $91 \%$ 로, 스마트폰의 영향이 큰 사회라고 볼 수 있다[3]. 손 안 에 들어오는 작은 도구를 매개로 실시간으로 정보를 확장하 고, 타인과 연결되며, 재미와 효율을 합친 ‘스마트한' 삶을 즐기고 있다 해도 과언이 아닐 것이다.

이렇듯 우리는 스마트폰을 사용하며 얻은 다양한 긍정적 인 변화를 피부로 느끼는 사회에서 살고 있으나, 지속적으로 제기되는 스마트폰 사용으로 인한 부정적 결과 또한 간과할 수 없다[4]. 보행 중 스마트폰을 사용하다 발생한 사고는 ‘스 몸비(smombie, 스마트폰 좀비)’라는 신조어까지 탄생시키며

Correspondence to Dai-Jin Kim, M.D., Ph.D.

Department of Psychiatry, Seoul St. Mary's Hospital, College of Medicine, The Catholic University of Korea, 222 Banpo-daero, Seocho-gu, Seoul 06591, Korea

Tel: +82-2-2258-7586, Fax: +82-2-594-3870, E-mail: kdj922@catholic.ac.kr

* This research was supported by the Brain Research Program through the National Research Foundation of Korea (NRF) funded by the Ministry of Science, ICT \& Future Planning (NRF-2014M3C7A1062893). 
세계 각국에서 일어나고 있고, 운전 중 핸드폰 사용은 교통 사고 위험의 주요 원인이다[5,6]. 목과 상지의 통증은 스마트 폰을 사용하면서 얻게 된 현대인의 고질병으로 통하고[7,8], 일부에서는 조절되지 않는 스마트폰 사용으로 인한 업무와 대인 관계에서의 기능 저하를 호소하기도 한다[9]. 뿐만 아 니라, 스마트폰을 사용하면서 발생한 기분 장애, 수면 불량 사례가 보고되며 단순한 사회 현상을 넘어 정신 건강을 저해 할 수도 있다는 우려 또한 존재한다[4,9,10].

본고에서는 의학적인 관점, 특히 중독 정신의학의 관점으 로 스마트폰 사용으로 인한 부정적 결과들에 접근해 보고자 한다. 아울러 현재까지 이에 관련하여 논의된 사항들을 검토 하여, 독자들이 ‘스마트폰 중독'에 대해 보다 폭넓게 이해할 수 있도록 돕고자 한다.

\section{스마트폰 중독의 정의}

스마트폰 사용으로 인한 부정적 결과들에 대해 학계에서 합의한 명칭은 현재까지 없으며, 여러 연구에서 ‘스마트폰 중독(smartphone addiction), ‘스마트폰 중독 경향(smartphone addiction proneness)', '스마트폰 과다사용(smartphone overuse)', '문제적 스마트폰 사용(problematic smartphone usage)' 등으로 다양하게 지칭된다[11-13]. 그러나 이들 용어 모두 공 통적인 뼈대는 행위 중독(behavioral addiction)이라는 '중독' 에서 기반하므로, 본고에서는 ‘스마트폰 중독(smartphone addiction)'으로 기술하고자 한다.

행위 중독은 중독을 중독물질 사용(substance use)의 결과 만으로 제한하여 보던 과거의 시각을 넘어, 비물질(non-substance)인 인간의 행동이 중독의 대상이 되어 많은 사람들이 조절되지 않는 행동으로 고통받을 수 있다는 개념이다[14]. 2013년 개정된 정신 장애의 진단 및 통계편람 5판(Diagnostic and Statistical Manual for Mental Disorders, DSM-5)에서 도박 중독(pathologic gambling)을 중독성 질환으로 분류함으로써 행위 중독은 정신 질환으로써 공인받았다[15]. 인터넷 중독 (internet addiction)으로 통칭되어 오던, 조절되지 않는 인터 넷 사용으로 인한 기능의 문제 또한 같은 해 DSM-5에서 게 임에 초점을 맞춘 인터넷 게임 장애(internet gaming disorder, $\mathrm{IGD}$ 로 진단 기준을 제시하며 향후 관심을 갖고 지켜봐야 할 임상 양상으로 제안되었다[15]. 스마트폰의 사용으로 인 한 부정적 결과들도 정신의학적 관점에서 인터넷 중독과 궤 를 같이 하는 인간-기계의 상호작용으로 인한 행위 중독으로
접근하려는 시도가 지속되고 있다[16]. 즉, 스마트폰 중독은 스마트폰 사용에서 중독의 주된 특징인 내성(tolerance), 금단 증상(withdrawal symptoms), 조절력 상실 등을 보이고, 이로 인해 일상 기능의 저하를 야기하는 상태로 볼 수 있다.

\section{진단과 평가}

스마트폰 중독에 대한 최적 표준진단(gold standard)이라 할 수 있는 진단 기준은 아직 제시되지 않았기 때문에, 본고 에서는 현재 연구에서 널리 쓰이며 국내 임상 현장에서 사용 할 수 있는 두 가지 자가평가 도구에 대해 소개하는 것으로 갈음하고자 한다.

한국정보화진흥원에서 개발된 한국형 스마트폰 중독 진 단 척도(smartphone addiction proneness scale, SAPS 혹은 S-척 도)는 인터넷 중독을 측정하는 기존 척도들을 기반으로 하 며, 총 15 문항으로 구성되어 있다. 하위 요인은 일상생활 장 애, 가상세계 지향, 금단, 내성으로 구성되며 문항에 따라 1점 부터 4점까지 응답할 수 있고, 설문 응답 값의 총합 또는 하 위 요인의 값을 기준으로 하여 고위험 사용자군, 잠재적 위 험 사용자군, 일반 사용자군으로 분류된다. 청소년용과 성인 용으로 구분되어 있어 연령층에 따라 각기 적용할 수 있다는 점이 특징적이다[17].

스마트폰 중독 측정 척도(smartphone addiction scale, SAS) 는 스마트폰 중독을 선별할 수 있는 33 개 문항으로 구성된 6점 척도이다. 하위 문항은 일상생활 장애, 스마트폰 사용에 대한 긍정적인 기대(positive anticipation), 가상세계 지향성, 과도한 사용, 금단, 내성으로 구성되어, 일반 컴퓨터와 구별 되는 스마트폰 이용 특성을 반영하였다[13]. 청소년을 대상 으로 한 10 문항으로 구성된 단축형 척도(SAS-short form version, SAS-SV)가 있으며, 성별에 따라 절단점이 다르다[18]. 단축형은 프랑스어와 스페인어 등 여러 언어로 번역되었으 며, 타당도 연구를 거쳐 국외 연구에서도 이용하고 있다 $[19,20]$. 이외에도 국내외 학자들이 개별적으로 제안하고 있 는 자가평가 척도들이 여럿 있으나, 중독 집단의 특성인 부 족한 병식(insight)으로 인해 임상적 진단과 낮은 일치도를 보일 수 있다는 제한점을 내포하고 있다[21].

\section{임상적 특징}

한국정보화진흥원에서 S-척도를 사용하여 파악한 국내 
스마트폰 중독 현황에 따르면, 2015년 스마트폰 중독 위험군 은 $16.2 \%$ (5,808,000명)로 조사 시작 이래 매년 증가하고 있 다[22]. 특히 청소년의 10 명 중 3 명이 스마트폰 중독 위험에 노출되어 있으며, 여성이 남성에 비해 전년 대비 높은 증가 폭을 보이고 있다는 점은 주목할 만하다[22].

스마트폰 중독 위험군의 스마트폰 이용 행태는 일반 사용 자와 차이를 보이는 것으로 알려져 있다. 하루 평균 스마트 폰 이용 시간의 경우, 중독 위험군은 301.4분으로 일반 사용 자군(269.7분)보다 길다[22]. 1일 평균 이용 횟수 또한 중독 고위험군은 61.7 회, 일반 사용자군은 40.8 회로 스마트폰 중 독 가능성이 높은 사람들이 더 빈번히 이용한다[23]. 이러한 상대적으로 높은 사용량과 사용 빈도는 중독의 보편적 특징 인 내성과 금단, 즉 스마트폰을 사용하며 즐거움 같은 긍정 적인 효과를 얻기 위해 점차 더 많이 스마트폰을 사용해야만 하고 어느 순간부터는 아무리 과다하게 사용해도 만족감이 없어지는 상황(내성)과, 스마트폰이 없으면 불안하고 초조함 을 느끼는 현상(금단)이 반영된 것일 수 있다. Lin 등[24]은 어플리케이션을 이용하여 측정한 결과 반복적으로 짧은 시 간 동안 스마트폰을 사용하는(frequent short-period use) 스마 트폰 중독군의 특성을 확인하였고, 이를 스마트폰 중독이 일 상을 저해하는 주된 기전으로 제안하였다.

스마트폰 중독과 관련된 다양한 임상 양상이 연구를 통해 보고되고 있으나, 스마트폰 중독이 확정된 의학 진단이 아닌 만큼 연구 설계 자체에 제한이 있을뿐더러 연구마다 보고된 내용이 상이하여 논쟁의 소지 또한 존재한다는 점을 상기해 야 할 것이다. 현재까지 보고된 스마트폰 중독과 연관되는 주요 양상은 여성, 낮은 연령대, 자기 조절 능력의 저하, 높은 충동성, 우울과 불안 증상 등이 있다[25-30]. 남성이 인터넷 게임 장애에 더 잘 이환되는 경향이 있는 것과는 대조적으로 스마트폰 중독은 여성과 관련성이 더 높다는 보고가 주를 이 루고 있으며, 이는 남성에 비해 소통 욕구와 사회성이 높은 여성이 스마트폰의 메신저 서비스와 사회관계망 서비스 (social network service, SNS) 등에 노출될 가능성이 더 높다 는 점과 연결지어 생각해 볼 수 있을 것이다[26,28-30]. 자기 조절 기능의 저하와 높은 충동성은 대부분의 중독 질환과 밀 접한 관련성이 있으며, 스마트폰 중독이 ‘중독'임을 뒷받침 하는 특징으로도 여겨진다[28,31]. 상대적으로 젊은 연령층, 특히 청소년이 스마트폰 중독과 관련이 있다는 보고 또한, 자기 조절과 충동성을 조절하는 기능이 아직 발달되지 않은 시기에 스마트폰에 장시간 노출됨으로써 위험성이 더욱 높
아질 수 있다[25,26]. 우울과 불안 같은 기분 증상과 스마트 폰 중독과의 연관성은 부정적인 기분을 완화하기 위한 수단 으로써 접근성이 매우 높은 스마트폰을 이용하며 중독이 발 생했을 가능성과, 스마트폰을 과도하게 사용함으로써 발생 한 금단증상 혹은 수면의 질 저하나 기능 저하에 따른 이차 적 현상일 가능성 등을 고려해야 한다[25-27]. 그러나 현재까 지 시행된 연구는 모두 단면 연구(cross-sectional study)이므 로, 관련 양상들과 스마트폰 중독의 선후 관계를 규명하기 위한 종단 연구(longitudinal study)가 반드시 필요할 것으로 보인다.

\section{치료와 예방}

스마트폰 중독이 공식적인 의학 진단이 아니기 때문에, 현 재까지 연구에 따른 근거에 기반한 체계적인 치료 가이드라 인이 마련되지 않아 기술하기에 어려움이 있다. 국내에서 수 행되었던 연구들은 중재 기법으로 기존의 중독 치료에서 사 용하던 동기강화 기법, 수용전념 치료 등의 심리 치료 기법 을 이용한 프로그램을 제안하였으나[32,33], 소수의 특정 집 단을 대상으로 시행하여 프로그램의 명확한 치료 효과는 확 인되지 않은 실정이다. 보건복지부에서 발행한 실무자 대상 안내서에는 인터넷 게임 장애와 함께 국내에서 제공할 수 있 는 스마트폰 중독 관리 서비스를 제시하고 있으나, 치료에 대한 부분은 인터넷 게임 장애에 주로 초점이 맞추어져 있는 경향을 보인다[34]. 그럼에도 불구하고 다른 행위중독들, 특 히 인터넷 게임 장애에서 좋은 효과를 보였던 생물-심리-사 회(biopsychosocial)적으로 통합한 정신의학적 치료 기법이 스마트폰 중독 치료에도 효과를 보일 것이라는 전망을 고려 한다면, 향후 이를 바탕으로 근거에 기반한 중재 프로그램 개발이 가능할 것으로 전망된다[35].

스마트폰 중독을 방지하기 위한 또 다른 주목할 만한 시 도는 스마트폰에 설치하는 모바일 어플리케이션(application, $\mathrm{App}$ )을 이용한 중재이다. 이는 정신건강 증진에 eHealth와 mobile Health (mHealth)를 적용한 방법론들의 급격한 성장으 로 더욱 탄력을 받을 것으로 보인다[36]. 현재 20종이 넘는 스마트폰 사용 중재 목적의 어플리케이션이 국내 시장에 소 개되었으며, 차단, 경고, 동기 강화 등의 기법을 이용하고 있 는 것으로 알려져 있다[37]. 특히 동기 강화 기법을 적용한 중재는 알코올 사용 장애나 담배 사용 장애 같은 '고전적' 중독에서도 의미 있는 치료 효과를 보이는 것으로 알려져 있 
어, 이를 정교화하고 고도화하는 것이 스마트폰 중독 치료 효과를 높일 수 있을 것으로 보인다[38]. 그러나 현재 연구 환경은 극소수의 어플리케이션들만이 임상적으로 검증되기 시작한 초창기 단계인 것을 감안한다면, 이들 어플리케이션 들의 스마트폰 중독 중재 효과나 적합성에 대한 정신건강 전 문가들의 깊이 있는 분석과 의학적 근거 확인에 대한 노력이 필요할 것이다[23,39].

\section{결 론}

스마트폰 중독은 현재로써는 의학적으로 확정된 진단명 은 아니나, 스마트폰을 사용하며 일어나는 부정적 결과들의 사회적 여파를 고려하였을 때 학계의 지속적인 관심이 필요 하다는 점에서는 이견이 없을 것으로 보인다. 스마트폰 중독 에 대한 연구가 초기 단계인 만큼, 질환에 대해 과학적으로 검증된 기초지식을 쌓는 데 우선 중점을 두어야 한다. 상술 하였듯 대규모 종단 연구가 스마트폰 중독의 발달 단계를 파 악하고 생물학적 기전을 발견하여 질환 체계를 확립하는 데 기여할 것으로 전망된다. 단순한 자가 보고를 넘어서는 보다 객관적인 평가 방법, 일례로 복합적인 스마트폰 이용 행태를 분석하여 문제적 행동 특성을 파악하는 데이터 마이닝 기법 또한 여기에 일조할 수 있을 것이다. 스마트폰 중독에 대한 보다 폭넓은 이해를 통해 개인과 사회의 고통을 경감시킬 수 있는 실질적인 치료 기법을 개발하고, 관련 보건 정책을 발 전시켜 건강한 스마트폰 이용에 기여할 수 있기를 희망한다.

중심 단어: 스마트폰 중독; 스마트폰 과다사용; 인터넷 중 독; 행위 중독

\section{REFERENCES}

1. Zheng P, Lionel N. Smartphone and next generation mobile computing. San Francisco: Morgan Kaufmann Publishers, 2010.

2. Ericsson. Ericsson Mobility Report [Internet]. Stockholm (SE): Ericsson AB, c2016 [cited 2016 Feb]. Available from: https://www.ericsson.com/res/docs/2016/mobility-report/ericsson-mobility-report-feb-2016-interim.pdf.

3. DIGIECO. 2016 Mobile Trend [Internet]. Seoul (KR): DIGIECO, c2016 [cited 2016 Aug 1]. Available from: http://www. digieco.co.kr/KTFront/report/report_main.action.

4. Lee YK, Chang CT, Lin Y, Cheng ZH. The dark side of smartphone usage: psychological traits, compulsive behavior and technostress. Comput Human Behav 2014;31:373-383.

5. Hookham M, Togoh I, Yeates A. Walkers hit by curse of the smombie [Internet]. London (ENG): The Sunday Times, c2016 [cited 2016 Feb 21. Available from: http://www.thesundaytimes.co.uk/sto/news/uk_news/article1670471.ece.

6. Klauer SG, Guo F, Simons-Morton BG, Ouimet MC, Lee SE, Dingus TA. Distracted driving and risk of road crashes among novice and experienced drivers. N Engl J Med 2014;370:54-59.

7. Lee S, Kang H, Shin G. Head flexion angle while using a smartphone. Ergonomics 2015;58:220-226.

8. Jonsson P, Johnson PW, Hagberg M, Forsman M. Thumb joint movement and muscular activity during mobile phone texting - a methodological study. J Electromyogr Kinesiol 2011;21:363-370.

9. Mok JY, Choi WS, Kim DJ, et al. Latent class analysis on internet and smartphone addiction in college students. Neuropsychiatr Dis Treat 2014;10:817-828.

10. Turel O, Serenko A. Is mobile email addiction overlooked? Commun ACM 2010;53:41-43.

11. Billieux J, Maurage P, Lopez-Fernandez O, Kuss DJ, Griffiths MD. Can disordered mobile phone use be considered a behavioral addiction? An update on current evidence and a comprehensive model for future research. Curr Addict Rep 2015;2:156-162.

12. Kim D, Lee Y, Lee J, Nam JK, Chung Y. Development of Korean smartphone addiction proneness scale for youth. PLoS One 2014;9:e97920.

13. Kwon M, Lee JY, Won WY, et al. Development and validation of a smartphone addiction scale (SAS). PLoS One 2013;8:e56936.

14. Choi SW. Behavioral Addictions. Seoul (KR): NUN, 2013.

15. American Psychiatric Association. Diagnostic and statistical manual of mental disorders (DSM- $5^{\circledR}$ ). Arlington (US): American Psychiatric Pub, 2013.

16. Griffiths M. Does internet and computer "addiction" exist? Some case study evidence. Cyberpsychol Behav 2000;3:211-218.

17. National Information Society Agency. Development of Korean Smartphone Addiction Proneness Scale for Youth and Adults. Seoul (KR): National Information Society Agency, 2011: 85-86.

18. Kwon M, Kim DJ, Cho H, Yang S. The smartphone addiction scale: development and validation of a short version for adolescents. PLoS One 2013;8:e83558.

19. Noyan CO, Darçın AE, Nurmedov S, Yılmaz O, Dilbaz N. Validity and reliability of the Turkish version of the smartphone addiction scale-short version among university students. Anatol J Cardiol 2015; 16:73-81.

20. Lopez-Fernandez O. Short version of the smartphone addiction scale adapted to Spanish and French: towards a 
cross-cultural research in problematic mobile phone use. Addict Behav 2017;64:275-280.

21. McLellan AT, McKay JR, Forman R, Cacciola J, Kemp J. Reconsidering the evaluation of addiction treatment: from retrospective follow-up to concurrent recovery monitoring. Addiction 2005;100:447-458.

22. National Information Society Agency. 2015 The survey on internet overdependence. Seoul (KR): National Information Society Agency, 2015.

23. Bang JH. The effects of smartphone addiction management application on self-regulation and interpersonal relationship ability of university students. Journal of the Korea Entertainment Industry Association 2016;10:323-337.

24. Lin YH, Lin YC, Lee YH, et al. Time distortion associated with smartphone addiction: identifying smartphone addiction via a mobile application (App). J Psychiatr Res 2015;65:139-145.

25. Smetaniuk P. A preliminary investigation into the prevalence and prediction of problematic cell phone use. J Behav Addict 2014;3:41-53.

26. Choi SW, Kim DJ, Choi JS, et al. Comparison of risk and protective factors associated with smartphone addiction and internet addiction. J Behav Addict 2015;4:308-314.

27. Demirci K, Akgönül M, Akpinar A. Relationship of smartphone use severity with sleep quality, depression, and anxiety in university students. J Behav Addict 2015;4:85-92.

28. van Deursen AJ, Bolle CL, Hegner SM, Kommers PA. Modeling habitual and addictive smartphone behavior: the role of smartphone usage types, emotional intelligence, social stress, self-regulation, age, and gender. Comput Human Behav 2015;45:411-420.

29. Kim Y, Jeong JE, Cho H, et al. Personality factors predicting smartphone addiction predisposition: behavioral inhibition and activation systems, impulsivity, and self-control. PLoS One 2016;11:e0159788.

30. Randler C, Wolfgang L, Matt K, Demirhan E, Horzum MB, Beşoluk S. Smartphone addiction proneness in relation to sleep and morningness-eveningness in German adolescents. J Behav Addict 2016;5:465-473.

31. Kim SM, Huh HJ, Cho H, et al. The effect of depression, impulsivity, and resilience on smartphone addiction in university students. J Korean Neuropsychiatr Assoc 2014;53:214-220.

32. Choi EM, Kim MS. The effect of motivational interview oriented and cognitive behavioral group counseling for college students with smartphone addiction. Korean Journal of Counseling 2016;17:169-185.

33. Yu HG, Son CN. Effects of ACT on smartphone addiction level, self-control, and anxiety of college students with smartphone addiction. Journal of Digital Convergence 2016;14:415-426.

34. Ministry of Health \& Welfare. Prevention, Treatment, Aftercare Service Cuide for Internet/Game/Smartphone Addiction Problems 2016. Seoul (KR): Industry-Academic Cooperation Foundation, The Catholic University of Korea, 2016.

35. Andreassen CS, Pallesen S. Social network site addiction an overview. Curr Pharm Des 2014;20:4053-4061.

36. Lam LT, Lam MK. eHealth intervention for problematic internet use (PIU). Curr Psychiatry Rep 2016;18:107.

37. Ko M, Lee J, Yang S, Lee U. An analysis of mobile apps for intervening excessive smartphone usage: intervention method perspectives. HCI 2014:747-50.

38. Miller WR. Motivational enhancement therapy manual: A clinical research guide for therapists treating individuals with alcohol abuse and dependence. Darby (US): DIANE Publishing, 1995.

39. Anthes E. Pocket psychiatry. Nature 2016;532:20-23. 